\title{
TECNOLOGIAS DE (DES)INFORMAÇÃO E (IN)COMUNICAÇÃO NO CONTEXTO DO SABER COMUNICACIONAL INDÍGENA AMAZÔNICO
}

James León Parra MONSALVE ${ }^{1}$

Universidade Federal do Pará - UFPA

e-mail: jlpm@ufpa.br

Resumo: A compreensão dos processos atuais de comunicação nas organizações regionais indígenas na Amazônia passa, necessariamente, pela consideração de sua diferença respeito das sociedades nacionais. Neste sentido, o objetivo do artigo é desenvolver uma aproximação etnográfica do modo em que os seus saberes são postos nas práticas comunicacionais dessas organizações. A partir de uma revisão bibliográfica, assim como de pesquisa de campo, pôdese verificar a subsistência de obstáculos que são estrategicamente pensados e resolvidos nessas entidades.

Palavras-chave: Organizações indígenas, Amazônia, Comunicação

\begin{abstract}
Understanding the current communication processes in indigenous regional organizations in the Amazon necessarily involves the consideration of their difference respecting national societies. In this sense, the objective of this article is to develop an ethnographic approach to the way in which their knowledge is put in communication practices of these organizations. From a literature review, as well as field research, it was possible to verify the subsistence of obstacles that are strategically thought out and resolved in these entities.
\end{abstract}

Keywords: Indigenous organizations, the Amazon, Communication

\footnotetext{
${ }^{1}$ Doutor em Planejamento do Desenvolvimento pela Universidade Federal do Pará. Mestre em História pela Universidad Nacional de Colombia. Comunicador Social - Jornalista pela Universidad de Antioquia.
} 


\section{Introdução}

Em recente pesquisa doutoral procurou-se compreender a relação das reivindicações cidadãs das organizações regionais indígenas amazônicas e as Tecnologias de Informação e Comunicação (TICs). Uma primeira abordagem dessa relação focou aspectos infraestruturais e técnicos da comunicação, analisados sob a ótica da teoria do discurso (MONSALVE, 2015). Um olhar que se completou com a abordagem de aspectos etnográficos dessas práticas comunicacionais nas organizações.

Nessa medida, propõe-se aqui desenvolver uma aproximação do modo em que tais organizações percebem a informação e a comunicação no contexto de seu conhecimento tradicional. A primeira parte aprofunda na macro-temática dos meios ancestrais de informação e comunicação, atendendo o contexto sócio-cultural em que as suas atividades estão inseridas. A segunda aborda a perspectiva em que as organizações definem as TICs em relação a sua missão corporativa.

\section{Meios ancestrais de informação e comunicação}

No olhar indígena a natureza constitui uma fonte de informação e uma possibilidade de comunicação, assim como o espaço e a matéria para o desenvolvimento de meios e dispositivos destinados a sua realização. O rio, o ar, a chuva, o sol, a lua, as nuvens, as árvores, as pedras, as montanhas... a natureza toda fundamenta essas primeiras técnicas de obtenção e produção de informação e de articulação do comum no social. Nesse sentido, lembra-se especialmente o que diz Fabián Moreno, Publicitário do povo Nonuia e assessor de comunicação na Organização dos Povos Indígenas da Amazônia Colombiana (OPIAC):

o rio Caquetá é um canal de comunicação. Então sabemos que estamos guiados pelas mudanças em etapas do ciclo anual. E é funcional: a gente sabe que em julho chegam o frio do Brasil, para o caso de Araracuara; no caso de Pedrera chega por aí um pouco antes de julho, quinze dias antes. Isso já nos conecta com eles para fazer certas atividades de rituais, que é o que eles chamam "manejar o mundo", para prevenir doenças, para fazer algumas dietas, para fazer uma formação de rapazes no conhecimento, então, quando chega o frio nós sabemos que em Pedrera estão fazendo certos rituais e eles sabem que nós cá também estamos; se trata de uma

MARGENS - Revista Interdisciplinar Versão Digital - ISSN: 1982-5374
10 anos de Margens-Dossiê: Olhares para o campo... VOL.10. N. 15. Dez 2016. (p. 53-67) 
comunicação muito tradicional porque, claro, até Pedrera não chega o som do trocano... (Tradução nossa). ${ }^{2}$

A continuação detalha-se alguns desses meios e dispositivos que se desenvolveram historicamente na região a partir do conhecimento próprio.

\section{O mullu e o botuto}

Chamam a atenção os usos informacionais que davam já em tempos pré-colombianos às próprias espécies do mar. Os Inca conheceram e transformaram metais como o cobre, a prata e o ouro. Foram bons metalúrgicos. Embora nunca lhes dessem o valor monetário que sim lhes daria o mundo moderno. Todavia, antes deles, culturas como a Chavin, Cupisnique, Mochica, Lambaieque, Chimu e Chincha, davam já um valor sagrado e comercial, não a tais metais, mas a um molusco, considerado o "ouro vermelho" ou o "alimento dos deuses", o qual era usado cerimonialmente pelo povo Valdívia há 5.200 anos, na região sul do litoral equatoriano (LÓPEZ CUEVAS, 2005).

Foram assim aqueles metais menos apreciados do que um molusco da costa oeste americana, cuja dispersão abrange áreas que vão do Equador até a Califórnia. O mullu (Spondylus princeps), como chamaram os Inca essa espécie marinha de múltiplas protuberâncias e cor avermelhada, utilizou-se em variados rituais, adornos corporais e, até, como espécie monetária. As práticas rituais ligadas aos processos de produção agrícola e pecuária tinham no mullu um produto altamente valorizado, pois além de "alimentar aos deuses", o molusco estava associado ao saber em torno da climática, questão necessária ao correto planejamento e aprovisionamento das regiões do Pacífico sul-americano. ${ }^{3}$

López Cuevas (2005, p. 37, tradução própria) sugere que "é muito provável que as sociedades pré-colombianas tivessem alcançado quanto menos consciência desta associação

\footnotetext{
${ }^{2}$ Fabián Moreno. Entrevista concedida ao autor. Bogotá, maio 2013.

3 Surpreendentemente, na região de Manabí, como anota Martín-Ramos ([s.d.], p. 6): “Los sacerdotes valdivianos también pudieron conocer que puesto que el molusco solo se reproduce en aguas cálidas, noticias de su eventual presencia al sur de Tumbes (en las costas peruanas) era indicadora de un aumento de la temperatura del mar (claro síntoma del "fenómeno del Niño"), lluvias muy abundantes y una mala cosecha. Por el contrario, si la presencia de Spondylus sp., era o es escasa en esa región quiere decir que las aguas del norte (habitualmente calientes) han bajado su temperatura media. Esto genera un fenómeno inverso al del Niño, y con seguridad será un año de sequías. De este modo, el control de los avistamientos de mullu pudo ser muy importante para planificar las campañas agrícolas."
}

MARGENS - Revista Interdisciplinar 10 anos de Margens-Dossiê: Olhares para o campo... Versão Digital - ISSN: 1982-5374 VOL.10. N. 15. Dez 2016. (p. 53-67) 
entre as variações climáticas e as populações de Spondylus." Ou seja, que tais sociedades puderam reconhecer tendências ambientais, a partir das quais começaram a relacionar a climática com a produção agropecuária. Em nossa perspectiva, um processo que tinha a ver, certamente, com práticas hoje agrupadas no campo da informação.

Quanto ao botuto, assinala dois artefatos de amplificação sonora, usados historicamente pelas sociedades indígenas sul-americanas (fig. 1). Elas identificavam a concha-rainha (Eustrombus gigas) e as suas diferentes propriedades, entre elas, as de ampliação do raio de difusão de sons, com as atividades que competiam aos chasques ${ }^{4}$. De igual maneira, usava-se para convidar aos trabalhos coletivos, pois tinham o costume de, nos tempos da preparação da terra, do cultivo e da colheita, "subir-se de noite em atalaias ou torres que para este efeito havia feitas, e tocavam uma trombeta ou caracol para pedir atenção, e a grandes vozes diziam: 'Tal dia se lavram as terras dos deficientes; acuda cada um a sua pertinência'." (GARCILASO DE LA VEGA, 1976a, p. 217, tradução própria).

Mas, as transformações decorrentes da invasão europeia no Sul da América, minguaram esse tipo de costumes e acabaram com esse sistema de postagens dos chasques, desenvolvido pelos incas nos séculos XIV e XV. Processo que, ligado à introdução de gado feita ao longo do tempo, resultou numa transformação da cultura material dos povos sulamericanos. Uma mudança que temos nomeado como o botuto de ontem e o de hoje (fig. 1).

Figura 1 - O botuto ontem (a) e hoje (b)

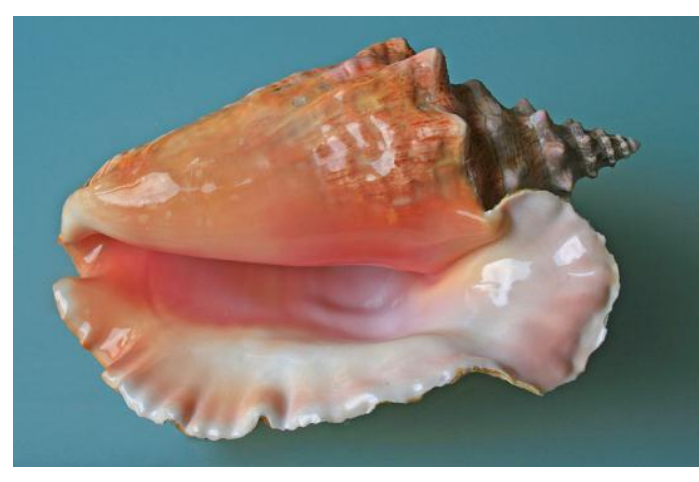

a

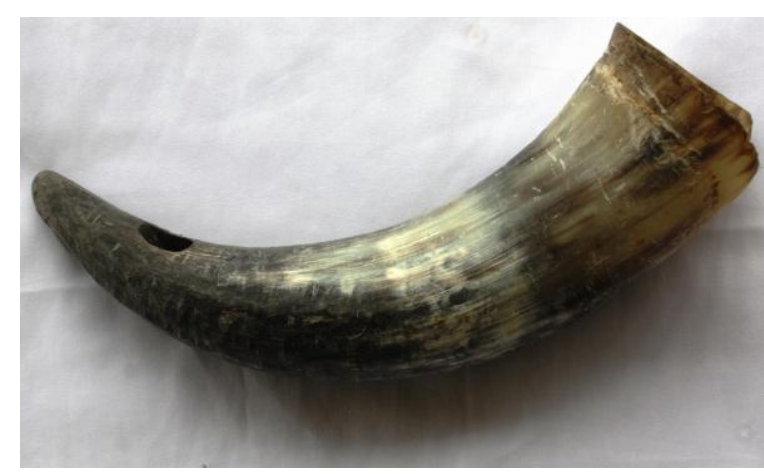

b

Fonte: (a) Wikipédia; (b) arquivo do autor

\footnotetext{
${ }^{4}$ Mensageiros, correios, do período incaico. MARGENS - Revista Interdisciplinar Versão Digital - ISSN: 1982-5374

10 anos de Margens-Dossiê: Olhares para o campo... VOL.10. N. 15. Dez 2016. (p. 53-67)
} 
Em outras palavras, hoje o botuto é mais aquele chifre-de-sopro, o que, virtualmente, emula o grande barulho que se pode atingir com a concha-rainha. Aparece ali uma mudança histórica que, assim seja funcional, perpassa um âmbito utilitário, pois os sentidos sociais e culturais ligados ao molusco não são os mesmos que os do chifre bovino, apesar deles compartilharem características físicas que os fazem apropriados à amplificação dos sons produzidos pela garganta e a boca humanas. Constituem, por isso, verdadeiras amostras de instrumentos e práticas sociais da comunicação antiga e hodierna na Amazônia, as quais, certamente, têm mudado através do tempo.

O botuto pode aparecer hoje para muitos como um artefato obsoleto. Contudo, se pensarmos com Sahlins (1983, p. 203, tradução própria) que o "que para a sabedoria herdada são condições «anti-econômicas» ou «exógenas», constituem, na realidade primitiva, a organização mesma da economia”, compreenderemos o errado desse juízo. Com certeza, no horizonte do modo capitalista de produção, trata-se de um artefato de museu, mas, considerando que na nossa Amazônia ainda existem outros modos como o extrativo ou o comunal, saberemos que o valor de uso desses instrumentos é ainda vigente em muitos cantos desse espaço sul-americano.

\section{De trocanos e manguarés}

No entanto, se o mullu e o botuto foram ou são vitais nas práticas e saberes ancestrais ou atuais dos povos indígenas, outras formas de difusão da informação também se desenvolveram em outros setores amazônicos. É o caso do trocano. Trata-se de um instrumento feito a partir do toro de uma árvore grande, num processo que se desenvolve ao longo de meses investidos na sua feitura; é chamado de manguaré pelo povo Múrui na Amazônia colombiana e peruana e trocano na brasileira.

Para Délio Alves, além de o trocano ser um meio de comunicação é um instrumento sagrado, graças às suas qualidades na geração desse "barulho grandioso", que possibilita(va) a comunicação sonora entre aldeias espalhadas na floresta amazônica (informação verbal) ${ }^{5}$. Efetivamente, com esse instrumento de percussão, os povos conseguem facilmente difundir

\footnotetext{
${ }^{5}$ Délio Alves. Entrevista concedida ao autor. Manaus, jul. 2013.

MARGENS - Revista Interdisciplinar 10 anos de Margens-Dossiê: Olhares para o campo... Versão Digital - ISSN: 1982-5374 
sons num raio longínquo, até atingir comunidades próximas. Segundo Gonzales Grández (2011, não paginado), seu som pode ser escutado até uns 20 quilômetros de distância. Daí que se possa concebê-lo como uma ferramenta tradicionalmente eficaz em muitas aldeias.

Entre os Múrui é comum o uso do manguaré. Manguaré fêmea e manguaré macho, para ser mais exatos, capazes de produzir sons de tons diferenciados pela forma específica de cada um deles (fig. 2). Bate-se neles com um pau que tem no final um grosso recobrimento de borracha. A sua feitura é um acontecimento de suma importância para as sociedade indígenas, pois reproduz e cristaliza um conhecimento que seus ancestrais perpetuaram até hoje, por meio do saber e a prática transmitidos de geração em geração.

Figura 2 - Manguarés Múrui (macho e fêmea, respectivamente)
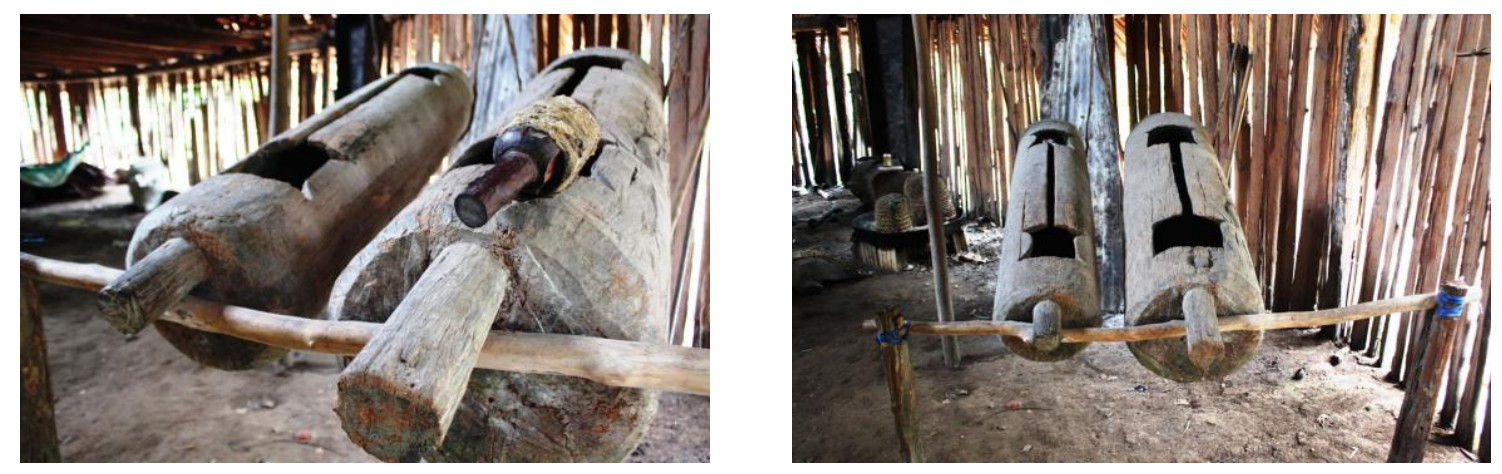

Fonte: Arquivo do autor

Desse modo, o manguaré ou trocano, constitui um artefato de percussão que viabiliza ações de comunicação tradicionalmente eficazes às necessidades informativas e de comunicação no nível local, isto é, das comunidades da floresta e suas vizinhas próximas. Certamente, não poderíamos dizer que se trate de um instrumento primitivo ou historicamente superado, pois, segundo Leandro Candapeña o uso de instrumentos de percussão feitos a partir de madeira ainda é comum no Chaco e na Amazônia bolivianos, sendo utilizados para o chamado a cerimônias espirituais, reuniões e assembleias. ${ }^{6}$

Acreditamos que esse artefato das sociedades amazônicas só chegou a existir e permanecer graças ao desenvolvimento de modos comunitários ou comerciais simples de

\footnotetext{
${ }^{6}$ Leandro Candapeña. Entrevista concedida ao autor. Santa Cruz de la Sierra, dez. 2012.

MARGENS - Revista Interdisciplinar 10 anos de Margens-Dossiê: Olhares para o campo... Versão Digital - ISSN: 1982-5374

VOL.10. N. 15. Dez 2016. (p. 53-67)
} 
produção. É difícil mesmo imaginarmos que povos isolados ou em contato inicial tenham por costume fazer manguarés, pois o seu grande peso e o cuidado de que precisam seriam insustentáveis para a maneira em que eles produzem e se reproduzem na floresta amazônica.

\section{Ecos e cantos entre os Tacana e os Aioreo}

Desde a antiguidade os indígenas concebiam os rios como limites naturais e davam nomes específicos em sua língua aos acidentes geográficos ${ }^{7}$ (sítios sagrados) existentes em seus territórios. O que se passa com cada um dos elementos da imensidão florestal, passíveis de se tornarem objetos do saber-fazer indígena. Um saber estreitamente ligado ao desenvolvimento das linguagens, especialmente das orais, como fator essencial da produção e a reprodução de suas culturas, ao final, de suas sociedades.

Por isso, em contextos mais localizados dessa imensidão, o eco cumpre cabalmente como técnica de comunicação de curta distância. A partir de uma ação em cadeia, em que a informação vai-se repetindo em cada elo, os aldeãos articulam uma velha prática sociocultural de se comunicarem em espaços locais. Trata-se de uma forma que ainda utiliza o povo Tacana, nas terras baixas bolivianas, para se passarem impressões orais por meio da voz humana que viaja rapidamente pelo espaço próximo: "Em alguns povos para uma comunicação interna podia ser também o eco, em cadeia, é dizer, eram vários vozeiros. Pronunciava aqui, repetia outro mais além, repetia outro mais além. Essa era uma forma, por exemplo, em meu povo.” (Tradução nossa) (Informação verbal). ${ }^{8}$

Mas, as línguas, que verdadeiramente possibilitam a comunicação oral, não podem ser reduzidas às meras contingências do presente ou restringidas aos âmbitos locais. Elas são um dos aspectos essenciais na vida das culturas originárias. É assim que, entre os Aioreo, que moram tanto na Bolívia como no Paraguai, o canto converteu-se num modo de transmissão de conhecimento e informação; em palavras de Rolando Bueno, liderança indígena da Confederação de Povos Indígena da Bolívia (CIDOB):

\footnotetext{
${ }^{7}$ Essas e outras considerações sobre a informação geográfica e os povos indígenas peruanos derivam das conversas feitas na Associção Inter-étnica de Desenvolvimento da Floresta Peruana (AIDESEP) com Sergio Loaiza e Waldir Eulogio Azaña. Entrevistas concedidas ao autor. Lima, dez. 2012.

${ }^{8}$ Emar Francisco Raldes. Entrevista concedida ao autor. Santa Cruz de la Sierra, dez. 2012.

MARGENS - Revista Interdisciplinar 10 anos de Margens-Dossiê: Olhares para o campo... Versão Digital - ISSN: 1982-5374

VOL.10. N. 15. Dez 2016. (p. 53-67)
} 
E o povo Aioreo, por exemplo, como eles transmitiam a sua informação o a sua realidade? Uma pessoa viajava de aqui ao Paraguai, onde há aioreos também, e chegava aqui e esse se sentava embaixo de uma árvore e começava a cantar, é dizer, não lhes contava falando senão que contava cantando numa canção o que tinha vivido e o que lhe tinham transmitido. (Tradução nossa) (Informação verbal). ${ }^{9}$

Assim, os cantos aioreos reproduzem a sua história coletiva, a sua própria cultura, sob impressões sonoras articuladas pela voz humana. O que nos lembra dos usos dados ao canto também num contexto incaico, tal e como se anota ao respeito:

As canções que compunham de suas guerras e façanhas não as interpretavam, porque não se devia cantar às damas nem dar conta delas por suas flautas. Cantavam-nas em suas festas principais e em suas vitórias e triunfos, em memória de seus acontecimentos façanhosos. (GARCILASO DE LA VEGA, 1976a, p. 113, tradução própria).

Usos da memória que Le Goff (2013, p. 391) considera sob a expressão 'memória étnica'; aquela dos povos sem escrita, memória coletiva que se interessa, mormente, pelos "conhecimentos práticos, técnicos, de saber profissional", constatando-se "raramente a existência de procedimentos mnemotécnicos nestas sociedades (um dos casos raros é o quipo peruano, clássico na literatura etnológica)"; memória que parece funcionar "segundo uma 'reconstrução generativa' e não segundo uma memorização mecânica." Por isto, afirma, certamente, que "enquanto a reprodução mnemônica palavra por palavra estaria ligada à escrita, as sociedades sem escrita, excetuando certas práticas de memorização ne varietur, das quais a principal é o canto, atribuem à memória mais liberdade e mais possibilidades criativas.” (LE GOFF, 2013, p. 393-394).

\section{A comunicação interpessoal}

A dispersão de comunidades e grupos existentes na Amazônia, assim como o predomínio da linguagem oral nesse âmbito, fazem com que em muitas delas se prefira a comunicação direta entre as pessoas. Os "vozeiros" ou pessoas encarregadas dessa prática de difusão oral nas comunidades são, geralmente, as próprias autoridades indígenas nas aldeias:

Dentro do mundo nosso, alguns de nossos irmãos, às vezes, querem que a gente vá pessoalmente a lhe dizer, olha, tal dia temos a reunião. E, então,

\footnotetext{
${ }^{9}$ Rolando Bueno. Entrevista concedida ao autor. Santa Cruz de la Sierra, dez. 2012.

MARGENS - Revista Interdisciplinar 10 anos de Margens-Dossiê: Olhares para o campo... Versão Digital - ISSN: 1982-5374

VOL.10. N. 15. Dez 2016. (p. 53-67)
} 
passe a voz. Eles têm essa forma de se comunicarem, esse povo, digo eu. Então muitos dos que desconhecem esta área de trabalho de povos indígenas e como o vão fazer, acalma-te!, que isso, se é amanhã o evento, amanhã te aparece toda essa gente. Isso tem a sua forma e a cadeia de como têm sido as suas comunicações. Isso é um povo que maneja essa forma, essa cadeia de comunicação, transmite-o à autoridade e a autoridade encarregase de passar a voz. (Tradução nossa) (Informação verbal). ${ }^{10}$

Conforma-se assim uma cadeia, como no supradito caso do eco, onde as informações fluem pelos corpos que articulam impressões orais e, consequentemente, fluem pelo corpo social. A questão da interação pessoal na comunicação é, dessa maneira, valorizada positivamente por alguns povos que confiam fortemente nela. Com razão, pois esses espaços internos constituem verdadeiros momentos de articulação das suas reivindicações e resistências. A comunicação presencial continua a ser assim um modo preferido em muitas aldeias, pois dessa forma também se criam e se afirmam vínculos sociais estratégicos para essas comunidades e povos. Além disso, a carência de infraestruturas adequadas para a internet e outros meios faz com que seja essa a única opção viável de se compartilhar a informação em áreas remotas dos centros mais populosos da bacia amazônica.

\section{De chasques e quipos}

A consolidação de um modo de produção tributário no oeste da bacia amazônica, a partir da estruturação do estado e o território incaicos, permitiu a aparição de formas mais desenvolvidas de informação e comunicação. Trata-se dos chasques e dos quipos. Segundo Rolando Bueno (informação verbal) ${ }^{11}$ :

Os chasques viajavam levando mensagens e os levavam numas cordas que tinham nós, esses são os quipos, e cada nó tinha uma significação, tinham até uma cor, se era para guerra tinha uma cor, se era para transmitir festejo tinha outra cor, e esses chasques corriam quilômetros, viajavam praticamente. (Tradução nossa).

Chasques e quipos formaram parte de verdadeiros sistemas de postagem e processamento de informação eficazes no seu momento. Segundo Garcilaso de la Vega (1976b, p. 22) os chasques encarregavam-se de levar os mandatos do Inca e de trazer avisos

\footnotetext{
${ }^{10}$ Ninfa Tividor. Entrevista concedida ao autor. Puerto Ayacucho, jul. 2013.

${ }^{11}$ Rolando Bueno. Entrevista concedida ao autor. Santa Cruz de la Sierra, dez. 2012.

MARGENS - Revista Interdisciplinar 10 anos de Margens-Dossiê: Olhares para o campo... Versão Digital - ISSN: 1982-5374 
e notícias importantes de todo o seu reino (o Tauantinsuio). Eles percorriam longas distâncias, através de diversos postos (tambos) espalhados pelos caminhos desse grande território.

Respeito dos quipos, podiam-se usar, por exemplo, para levar estatísticas sobre o número de gado nos seus territórios, pois, segundo o autor:

Tinham conta do número de todo esse gado bravo como se fosse manso, e nos quipos, que eram os livros anais, o registravam por suas espécies, dividindo os machos das fêmeas. Também tombavam o número de animais que tinham morrido, assim dos selvagens danosos como dos proveitosos, para saber as cabeças que tinham morrido e as que ficavam vivas, para ver na caçada seguinte o que se tinha multiplicado. (Tradução nossa) (GARCILASO DE LA VEGA, 1976b, p. 21).

Mas não só eles davam conta do gado por meio desse dispositivo. A administração de justiça nesse período armazenava e compartilhava informação da sua incumbência, desde os níveis locais até os superiores, através de quipos:

A maneira de dar esses avisos ao Inca e aos de seu Conselho Supremo era por nós em cordões de diversas cores, que eles entendiam como cifras. Porque os nós de tais e tais cores diziam os delitos que se tinham castigado, e, certas cordinhas de diferentes cores atreladas aos cordões grossos, diziam a pena que se tinha dado e a lei que se tinha executado. (Tradução nossa) (GARCILASO DE LA VEGA, 1976a, p. 88).

A ampla rede de trilhas e caminhos que percorria América do Sul, na época do Inca Garcilaso, apenas se começa a descobrir e compreender. Daí a importância desse texto que descrevia já no início do século XVII um dispositivo material como os quipos. Certamente, o quipo foi um mecanismo de memória, portanto, de informação e comunicação. Isto é, foi tradicionalmente eficaz para produzir e reproduzir informação sobre terras, gado, obras, provisões, postagens, entre outras, essenciais ao modo tributário, nessa área andinoamazônica, ligado aos diversos lugares dependentes do Cusco pré-colombiano.

O quipo, em termos de dispositivo ou prática discursiva é ligado ao trabalho do quipocamaio, quem, nesse tipo de cordões, sintetizava diversas informações e decisões administrativas, ações relativas ao funcionamento da estrutura estatal incaica. Se pensarmos que houve uma quantidade suficiente de servidores a desenvolver uma tarefa, até certo ponto, "informática", começaremos a entender a estratégica de informação e comunicação por trás MARGENS - Revista Interdisciplinar Versão Digital - ISSN: 1982-5374 
desse território que, em seu tempo, agrupou áreas hoje limitadas pelas repúblicas da Colômbia, Peru, Equador, Bolívia, Chile e Argentina, abrangendo uma parte do que atualmente chamamos de Pan-Amazônia.

Por enquanto, devemos pensar que esses diversos dispositivos, assim não façam parte das próprias atividades que hoje desenvolvem as organizações nos seus escritórios regionais, são parte desse espaço do que pode e deve ser dito, isto é, da formação discursiva que delimita esse saber comunicacional indígena. Por isto, noções como trocano, manguaré ou chasque aparecem no interdiscurso que nos lembra dessa condição diferenciada em que eles se desenvolveram. Em consequência, o percurso linear da teoria mais tradicional da comunicação, que se vangloria no jogo da mensagem entre um emissor e um receptor, fica aquém de uma crítica rigorosa dessa prática sócio-cultural, e os marcos de ação das sociedades ocidentais tendem a mostrar cada dia mais essa carência.

\section{Organizações regionais indígenas e tecnologias de (des)informação e (in)comunicação}

Tal e como apontou Manxineru (2008) numa nota sobre a questão da cidadania e o eleitor indígena, as TICs não deveriam ser enxergadas sob uma ótica meramente informacionalista, mas respeito de processos de desinformação e incomunicação que, real ou potencialmente, menoscabam o exercício político que implica uma cidadania substantiva e ativa. Uma que não iguale só política, mas economicamente, onde o cidadão não tenha de ser representado (WOOD, 2000), ainda menos, em termos produtivos.

Nesse contexto, são gritantes as formas em que ainda alguns setores sociais se valem de estratégias que historicamente têm deformado esses sujeitos coletivos que são os povos indígenas. Contudo, uma contra-estratégica está estruturando os caminhos alternos dos movimentos sociais. É aqui que pronunciamentos das organizações, denunciando assassinatos, lentidão e descaso na demarcação e homologação das terras indígenas, falta de consulta prévia e informada, entre outras, espalham-se no ciberespaço, criando novas relações de solidariedade, conhecimento e reconhecimento, praticamente impossíveis de imaginar no contex to homogeneizador do mercado e dos estados nacionais.

Sublinha-se também a relação especial com a natureza, com a terra, que aqui se considera o meio de produção e reprodução social por excelência, a qual continua a ser MARGENS - Revista Interdisciplinar 10 anos de Margens-Dossiê: Olhares para o campo... Versão Digital - ISSN: 1982-5374 VOL.10. N. 15. Dez 2016. (p. 53-67) 
essencial na existência e na resistência das culturas amazônicas. E, ligada a ela, os saberes tradicionais sobre esse ambiente amazônico, onde mais do que informação ou conhecimento passíveis de direitos de propriedade intelectual, enxergam-se práticas coletivas de saber e de manejo dos recursos comuns. Como se disse anteriormente, acham-se ali ainda formas do trabalho comum (minga ou mutirão) e relações de reciprocidade que embasam as práticas ligadas à construção e uso de malocas, artefatos como o trocano, o tipiti, o iapurutu, ou, inclusive, de completos sistemas agropecuários ou de irrigação, como aqueles vestígios vivos dos vales dos rios Apurímac e Urubamba.

Destaca-se, por isso, a transversalidade das práticas informativas e comunicativas nesse quadro organizacional avaliado. Onde é vital tanto o saber sobre o "manejo do mundo"12 como aquele da estratégica corporativa de comunicação. Por isto, a maioria das lideranças indígenas entrevistadas sabe que não é da mesma cidadania que falam quando outros falam dela. Que os seus modos de vida resistem, justamente, no seu confronto com os marcos regulatórios democrático-liberais. De maneira que é preciso continuar a refletir em torno desses dispositivos da cultura material contemporânea, sob uma ótica diferenciada.

É assim que as TICs são matéria de interesse nessas organizações. Porque, se de um lado as diretorias conhecem essas dinâmicas comunitárias da comunicação, por outro, elas precisam manterem vínculos com outros públicos diversos. Aspectos que têm sido valorizados com maior resolução nessas entidades nos últimos lustros. Evidencia-se logo a transcendência que hoje tem para elas a sua presença na internet, face ao mundo exterior, e no estabelecimento de comunicações internas, com as organizações de base e suas respectivas comunidades, e com os demais agentes sociais envolvidos nas suas atividades corporativas.

Frisa-se, aliás, uma relação entre tecnologia, natureza e necessidades dos povos indígenas amazônicos, o que representa um argumento a mais na análise das dinâmicas específicas em matéria de informação e comunicação nessa região. Explica-se. A tecnologia, como anota Délio Alves, é relativa, a se fazer na própria aldeia; em suas palavras:

A tecnologia para mim, na minha visão, ela é importante, mas ela não é tudo, né? Porque para mim viver para mim ter saúde, por exemplo, eu não precisaria da tecnologia do mundo branco, porque tudo do que eu preciso:

\footnotetext{
${ }^{12}$ Manejo cristalizado em diversos rituais que reproduzem saberes e conhecimentos ancestrais (informação verbal). Fabián Moreno. Entrevista concedida ao autor. Bogotá, maio 2013.

MARGENS - Revista Interdisciplinar 10 anos de Margens-Dossiê: Olhares para o campo... Versão Digital - ISSN: 1982-5374 VOL.10. N. 15. Dez 2016. (p. 53-67)
} 
comida, terra, floresta, água, eu tenho na minha aldeia, então a tecnologia para mim ela é feita na minha aldeia. Se eu preciso de uma panela, por exemplo, claro, se eu vou lá eu pego o barro e faço uma panela, se eu preciso de comida eu não preciso ir no supermercado pegar o carrinho e comprar, a natureza já me dá a comida; então a tecnologia no mundo indígena ela é relativa, então, nós temos a nossa tecnologia, nosso povo, nós temos a nossa ciência, a minha ciência, por exemplo, não é nem melhor nem pior do que a ciência do mundo branco. (Informação verbal). ${ }^{13}$

Uma distinção que é reforçada nos confrontos e antagonismos vividos quando chegam nas cidades amazônicas desde o interior, onde o modo capitalista quiçá pode ter até agora uma menor influência na vida das pessoas. Mas, com a chegada na cidade, o processo de se mergulhar numa outra dinâmica cultural, alheia às suas próprias sociedades, é acelerado:

no mundo hoje, tecnológico, mais moderno, onde eu tô vivendo, numa cidade, onde têm pessoas indígenas, não-indígenas e que os conflitos eles não são aparentes, eles realmente existem, nós precisamos nos adequar a essas tecnologias. E aí, como nós estamos hoje num mundo em que nós precisamos também divulgar, comunicar, o sofrimento ou a violação dos direitos, nós precisamos usar essas ferramentas que existem e que são feitas pelos não-indígenas, por exemplo. E essas tecnologias nos ajudam muito, a questão, por exemplo, de a gente fazer um jornalzinho, ir imprimir e entregar para as autoridades, para as pessoas que não conheçam nossa causa e aí a gente já usufrui da tecnologia que não é nossa mas que nos ajuda, né? Usufrui, por exemplo, da tecnologia hoje do e-mail, que não é nossa, mas nos ajuda, usar da tecnologia do telefone que não é nossa, mas nos ajuda. Então a gente tem que fazer essa associação da tecnologia e as necessidades atuais dos indígenas, sempre fazendo essa comparação, mas sempre tendo essa noção de diferenciação. ${ }^{14}$ (Grifo do autor).

Usar as TICs para comunicar, divulgar a violação dos direitos, o sofrimento, é a questão. Délio sublinha a relação entre tecnologia e necessidades dos indígenas. Na sua fala encontram-se as pegadas da cidadania segundo uma lógica democrático-liberal, mas não só. Se lembrarmos da constituição do subjetivo na enunciação (ou da prática comunicativa em geral), constituição certamente sócio-histórica, facilmente saberemos que o brutal recalcamento com que a modernidade nos distancia da configuração dos sujeitos e dos

\footnotetext{
${ }^{13}$ Délio Alves. Entrevista concedida ao autor, Manaus, jul. 2013.

${ }^{14}$ Délio Alves. Entrevista concedida ao autor. Manaus, jul. 2013.

MARGENS - Revista Interdisciplinar 10 anos de Margens-Dossiê: Olhares para o campo... Versão Digital - ISSN: 1982-5374 VOL.10. N. 15. Dez 2016. (p. 53-67)
} 
sentidos (mecanismo que nos ilude, até o ponto de crer que o eu é a sua fonte e fundamento), é ali atenuado pelo contexto societal em que para ele a tecnologia adquire algum sentido. Em outras palavras, o nós da sua enunciação não se poderia restringir ao agente organizacional que ele representa, mas ao âmbito em que como povos indígenas diferenciam-se numa luta também contra-ideológica, perante o individualismo moderno. Correndo o risco de simplificar demais o nosso argumento, diríamos que ao 'penso, logo existo', contrapõe-se ali o 'pertenço, logo existo'.

\section{Referências}

GARCILASO DE LA VEGA, I. Comentarios reales I. Caracas: Fundación Biblioteca Ayacucho, 1976a.

Comentarios reales II. Caracas: Fundación Biblioteca Ayacucho, $1976 b$.

GONZALES GRÁNDEZ, D. El manguaré. Disponível em: <http://escritoresamazonicos.blogspot.com/2011/02/el-manguare-demostenes-gonzalesgrandez.html>. Acesso em: 30 jan. 2015.

LE GOFF, J. História e memória. Trad. Bernardo Leitão; Irene Ferreira; Suzana Ferreira Borges. 7. ed. Campinas: UNICAMP, 2013.

MANXINERU, T. $\mathrm{S}$. $\mathrm{H}$. $\mathrm{O}$ eleitor indígena. Disponível em: <file:///home/james/Documents/OrgIndNov2012/www.coiab.com.br/coiab.php\%3Fdest=sh ow \&back=artigo\&id=218\&tipo=A\&pagina=3.html $>$. Acesso em: 14 nov. 2008.

MARTÍN-RAMOS, P. En busca del Spondylus. Rutas y simbolismo. [S.l.]; [s.d.].

MONSALVE, J. L. P. Las nuevas formas de La ciudadanía en la comunicación digital: reivindicaciones indígenas y TICs en la Panamazonia. Commons: Revista de Comunicación y Ciudadanía Digital, v. 4, n. 2, p. 155-185, dic. 2015.

LÓPEZ CUEVAS, F. El Spondylus en el Perú prehispánico. Su significación religiosa y económica. Ámbitos : Revista de Estudios de Ciencia Sociales y de Humanidades, n. 14, p. 33-42, 2005.

OLIVEIRA FILHO, J. P. de. Cidadania, racismo e pluralismo: a presença das sociedades indígenas na organização do Estado-Nacional brasileiro. Ensaios em antropologia histórica. Rio de Janeiro: UFRJ, 1999. p. 192-208.

MARGENS - Revista Interdisciplinar Versão Digital - ISSN: 1982-5374
10 anos de Margens-Dossiê: Olhares para o campo... VOL.10. N. 15. Dez 2016. (p. 53-67) 
WOOD, E. M. Democracy against capitalism : renewing historical materialism. Cambridge: Cambridge University Press, 2000.

MARGENS - Revista Interdisciplinar Versão Digital-ISSN: 1982-5374
10 anos de Margens-Dossiê: Olhares para o campo... VOL.10. N. 15. Dez 2016. (p. 53-67) 